\title{
Posterior Circulation Ischemic Stroke Secondary to High-Grade Glioma: A Rare Case Report and Review of the Literature
}

\author{
Konstantinos Kasapas ${ }^{1}$, Antonia Malli ${ }^{1}$, Eleni Kassioti ${ }^{2}$, Polytimi-Eleni Valkimadi ${ }^{2}$ \\ 1. Neurosurgery, Athens General Hospital "G. Gennimatas", Athens, GRC 2. Neurology, Athens Naval Hospital, Athens, \\ GRC
}

Corresponding author: Konstantinos Kasapas, kostaskasapas@gmail.com

\begin{abstract}
Neurological deterioration or new focal deficits in patients with primary brain tumors are usually related to intratumoral hemorrhage, disease progression, seizures (Todd paralysis) and, rarely, ischemic stroke. Ischemic strokes in this group of patients are usually a postoperative complication, a long-term result of radiation vasculopathy, embolic due to hypercoagulability and, less commonly, caused by vessel occlusion by an adjacent brain tumor. We report a rare case of ischemic stroke secondary to a newly diagnosed highgrade glioma and the possible mechanisms that resulted in this medical condition.
\end{abstract}

Categories: Neurology, Neurosurgery, Oncology

Keywords: high grade glioma, glioblastoma, posterior cerebral artery, ischemic stroke

\section{Introduction}

Neurological deterioration or new focal deficit in patients with primary brain tumors is usually related to intratumoral hemorrhage, disease progression, seizures (Todd paralysis) and, rarely, to ischemic stroke. Ischemic strokes in this group of patients are usually a postoperative complication, a result of radiation vasculopathy or embolic due to hypercoagulability. Furthermore, arterial ischemic stroke may be caused by vessel occlusion due to direct infiltration, encasement and occlusion of arterial branches by the adjacent brain tumor, direct tumor mass effect or leptomeningeal involvement. We report a rare case of posterior cerebral artery (PCA) stroke secondary to a newly diagnosed primary brain tumor, including a literature review on the topic.

\section{Case Presentation}

A 68-year-old man was admitted to the emergency department with sudden onset of left side muscle weakness accompanied by a four-day unsteadiness and bitemporal headache. The patient also mentioned a four-week history of dysphagia both in liquids and solids. Physical examination revealed a horizontal nystagmus in the left-eye-position, a reduced swallowing reflex, a left-sided hemiparesis with $4 / 5$ muscle strength and a left-sided dysmetria and asynergia. His past medical history included hypertension and dyslipidemia. The rest medical history was unremarkable.

The initial diagnostic workup included a brain computed tomography (CT) which revealed a right temporal lobe tumor extending into the basal ganglia as well. Further evaluation with a brain magnetic resonance imaging (MRI) revealed a highly vascularized tumor in the aforementioned area, with an irregular gadolinium ring enhancement and surrounding edema (Figure 1). 


\section{Cureus}

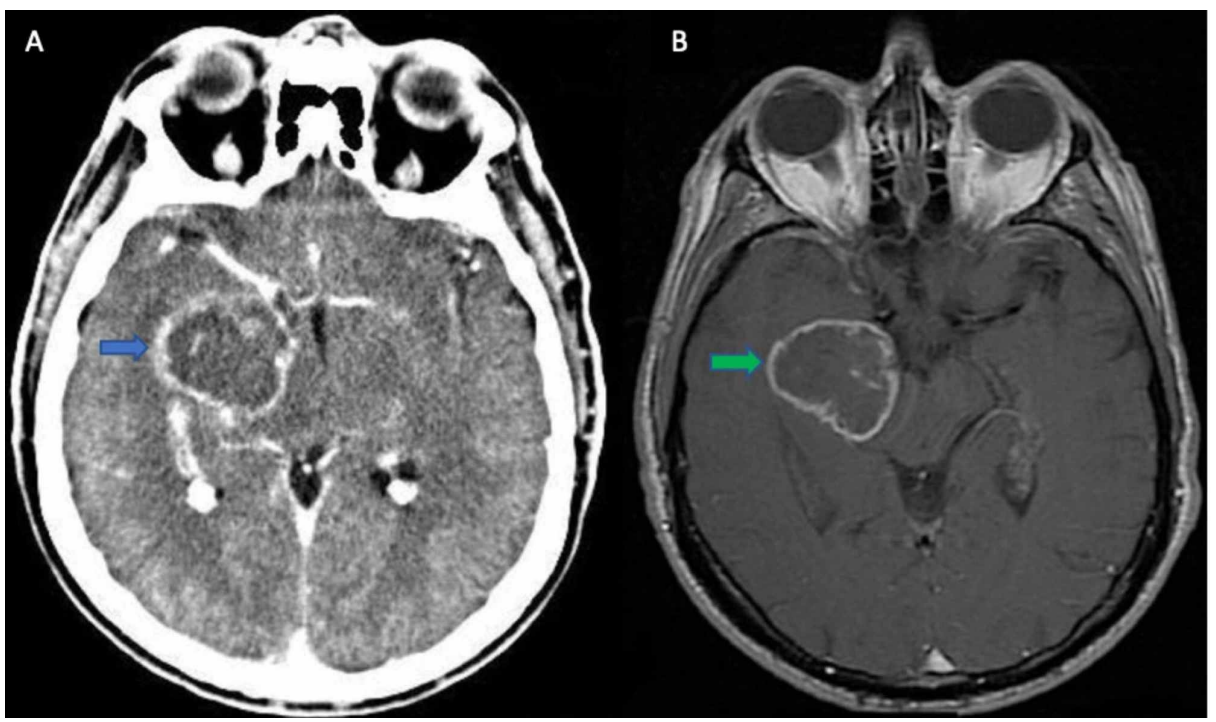

FIGURE 1: (A) CT brain axial with contrast showing a right temporal lobe tumor with an irregular ring enhancement (blue arrow). (B) MRI brain -T1 axial gadolinium (Gd) showing probably a high-grade glioma (green arrow)

At that moment, a diagnosis of a high-grade glioma was suspected. He was treated with high dosage of intravenous dexamethasone and clinical improvement was gradually noted. Even though a primary brain lesion was most likely the case, the patient also underwent thoracic and abdomen computed tomography and the possibility of a secondary brain tumor was excluded at that stage. In further investigation, the presence of a high-grade glioma, and probably a glioblastoma, was suggested by a magnetic resonance spectroscopy (MRS). During patient's hospitalization (day 3) a sudden neurological deterioration occurred as he developed a left hemianopia with a $2 / 5$ left-sided hemiparesis. The new brain CT scan revealed a new hypointense lesion in the right occipital lobe without hemorrhagic findings and the diffusion-weighted magnetic resonance imaging (DW-MRI) confirmed a recent right posterior cerebral infarct (Figure 2). Thrombolysis was not performed due to high bleeding risk of the tumor and secondary stroke prevention with acetylsalicylic acid was administered at that moment. Patient's neurological status, in terms of left-sided hemiparesis, was gradually improved and a few days later he was transferred to the neurosurgery department for surgery planning and further treatment with radiotherapy and chemotherapy.

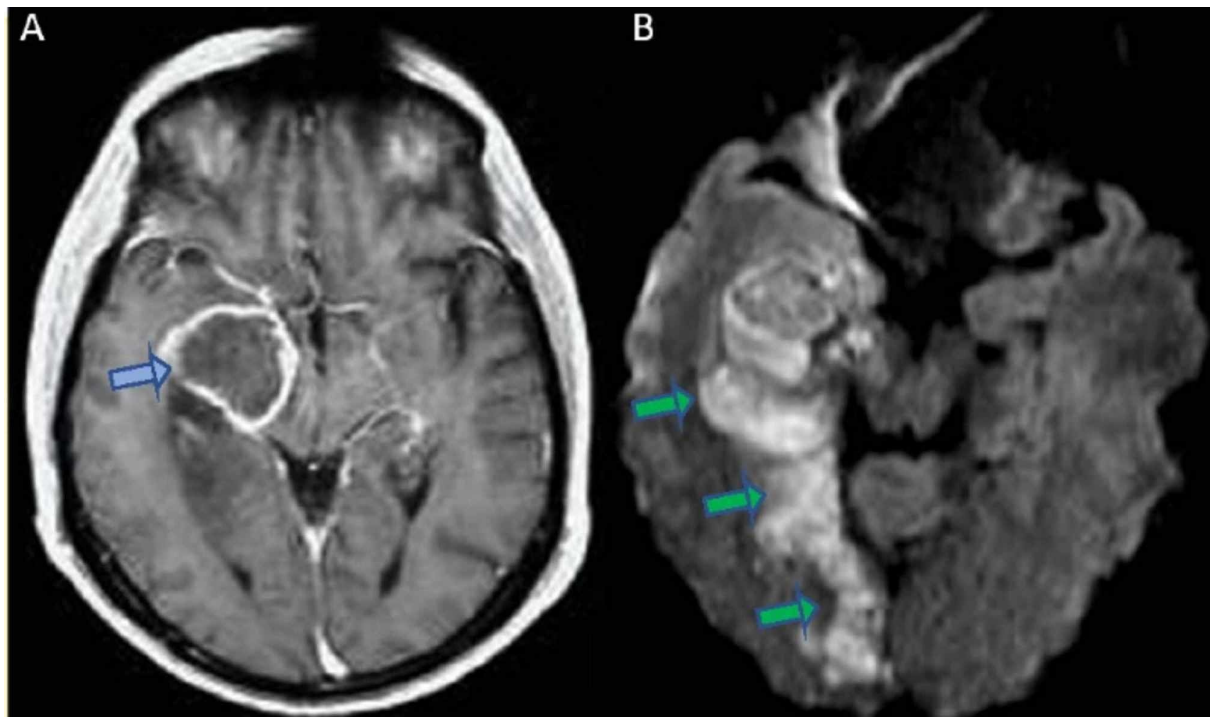

FIGURE 2: (A) MRI axial T1 gadolinium depicting a highly vascularized right temporal lobe tumor with an irregular ring enhancement (blue arrow). (B) DW-MRI scan showing a recent right posterior cerebral infarct in close proximity to the tumor (green arrows) 


\section{Discussion}

In the literature, the need for "tumor awareness" in the diagnostic work-up of patients presenting with the clinical picture of acute cerebrovascular disease, has already been emphasized. However, a probably more important question is the co-existence of stroke in a patient with primary brain tumor and the relation of those two conditions, as this implies appropriate therapeutic interventions. The number of such cases is not clearly known and it is often underestimated as there are stroke cases often asymptomatic and apparent only in neuroimaging [1].

Neurological deterioration in patients with primary brain tumor usually occurs due to tumor progression (edema, necrosis), intratumoral hemorrhage, seizures or cerebral ischemia. The last cause is not that common and is often underestimated. A sudden clinical manifestation suggests a rather vascular etiology, however, the diagnosis of ischemic stroke only on clinical grounds is challenging and imaging techniques play a major role. Follow-up imaging is often necessary as DW-MRI hyperintensities around the tumor area may be related to the tumor itself or prolonged seizure activity [2].

Our literature search revealed very few cases with high-grade glioma and a posterior cerebral artery infarct, showing the rarity of such cases (Table 1 ). In addition, most malignant cases were associated with middle cerebral artery territories, usually following surgical resection of the tumor.

\begin{tabular}{|c|c|c|c|}
\hline Study & Age - Sex & Associated cerebral infarct & Management of stroke \\
\hline Obeid et al. (2010) [2] & $\begin{array}{l}\text { 41-year-old, } \\
\text { Male }\end{array}$ & Left middle cerebral artery infarct & Observation \\
\hline Pina et al. (2014) [3] & $\begin{array}{l}\text { 77-year-old, } \\
\text { Female }\end{array}$ & Right middle cerebral artery infarct & Right anterior temporal lobectomy \\
\hline \multirow{2}{*}{$\begin{array}{l}\text { Rojas-Marcos et al. } \\
\text { (2005) [4] }\end{array}$} & $\begin{array}{l}\text { 60-year-old, } \\
\text { Male }\end{array}$ & Right middle cerebral artery infarct & No details \\
\hline & $\begin{array}{l}\text { 41-year-old, } \\
\text { Male }\end{array}$ & $\begin{array}{l}\text { Right supraclinoid segment of internal } \\
\text { carotid artery infarct }\end{array}$ & No details \\
\hline Farkas et al. (2018) [5] & $\begin{array}{l}\text { 58-year-old, } \\
\text { Female }\end{array}$ & Right middle cerebral artery territory infarct & $\begin{array}{l}\text { Aspirin and clopidogrel - Tumor resection } 2 \\
\text { months later }\end{array}$ \\
\hline \multirow{2}{*}{$\begin{array}{l}\text { Lasocki and Gaillard } \\
\text { (2016) [6] }\end{array}$} & $\begin{array}{l}\text { 58-year-old, } \\
\text { Female }\end{array}$ & Left posterior cerebral infarct & Resection of glioblastoma \\
\hline & $\begin{array}{l}\text { 61-year-old, } \\
\text { Male }\end{array}$ & Right middle cerebral artery infarct & $\begin{array}{l}\text { Intravenous thrombolysis with tissue } \\
\text { plasminogen activator }\end{array}$ \\
\hline Amelot et al. (2015) [7] & $\begin{array}{l}\text { 40-year-old, } \\
\text { Male }\end{array}$ & Left MCA infarct & Observation \\
\hline $\begin{array}{l}\text { Kamiya-Matsuoka et al. } \\
\text { (2015) [8] }\end{array}$ & Nine patients & Posterior cerebral artery infarct & No details \\
\hline Chen et al. (2011) [9] & $\begin{array}{l}\text { 58-year-old, } \\
\text { Female }\end{array}$ & Left middle cerebral artery infarct & $\begin{array}{l}\text { Resection of glioblastoma and } \\
\text { decompressive craniectomy }\end{array}$ \\
\hline
\end{tabular}

TABLE 1: Literature review for the cases of high-grade gliomas and subsequent cerebrovascular ischemic infarct

MCA: Middle cerebral artery

Patients with systemic cancer may develop a stroke in the context of a hypercoagulable state or nonbacterial thrombotic endocarditis (NBTE), both related to the malignancy itself. However, patients with brain tumors are not usually susceptible to these mechanisms. On the contrary, ischemic strokes in such patients are usually a postoperative complication, a late result of radiation therapy and/or chemotherapy and, less commonly, caused by vessel occlusion by direct compression, infiltration or encasement. There are also few case reports mentioning a high risk of strokes in patients receiving some certain anti-angiogenic 
In a retrospective study of 68 stroke patients with known brain tumors it was found that postoperative complications and radiation therapy accounted for $48 \%$ and $29 \%$ of stroke cases, respectively [11]. Large artery strokes accounted for $11 \%$ of nonpostoperative strokes and in the literature, other five cases of a temporal glioblastoma and a middle cerebral artery (MCA) stroke on the same side, have also been described [12-14].

Our patient was diagnosed with a right high-grade tumor and he subsequently developed a right PCA infarct a few days after the initial tumor diagnosis was made. This patient had not undergone surgical operation nor had received radiation therapy or chemotherapy at that moment. The possibility of in situ atherosclerotic disease of PCA cannot be fully excluded because of the medical history of hypertension and dyslipidemia. However, the fact that the stroke took place so soon after the initial brain tumor diagnosis and the intimate anatomical relation between the tumor and the artery, suggests a rather direct effect of the malignancy on the PCA.

There are three possible mechanisms regarding this and other relevant stroke cases with brain tumor; mechanical compression, vessel infiltration by cancer cells and local procoagulant effect due to tumorsecreted chemical factors. None of these mechanisms can be rejected from a single case report; however, a local hypercoagulant state may be more possible due to the procoagulant secreting properties of high-grade gliomas that are well-described in the current literature [15].

Intravenous thrombolysis is the only possibly effective treatment for early cerebral ischemia but the presence of an intracranial tumor has always been a contraindication because of the increased intracranial bleeding risk [16]. There are five reports so far with IV recombinant tissue plasminogen activator (r-TPA) administration in patients with intracranial neoplasms mentioning that the presence of a presumably benign neoplasm may not necessarily contribute to an unfavorable outcome and this therapeutic option should probably be kept in mind [16]. However, the number of cases is far too small and more published cases are definitely necessary [2-9].

Stroke in brain tumor patients is a frequently missed diagnosis and this leads to incomplete or even wrong evaluation and treatment. Despite this rarity, clinicians should be alert regarding this potential complication, as a false interpretation of neurological deterioration may lead to inappropriate change of antitumor therapy. In addition, while most patients have an already significant morbidity from the tumor itself, cerebral ischemia may still compromise outcome and quality of life of these patients.

Secondary prevention, when possible, should not be neglected and thrombolysis should be carefully evaluated in an individualized-patient setting due to the propensity of primary intracranial malignant neoplasms to bleed spontaneously. Last but not least, prospective studies need to be conducted to assess the treatment modalities in patients with acute stroke and a newly-diagnosed primary brain tumor.

\section{Conclusions}

Our report describes a rare case of PCA stroke secondary to a newly diagnosed primary brain tumor. It emphasises the need of alertness for identifying other potential causes, apart from tumor progression, in such patients when clinical deterioration is observed. A precise diagnosis is necessary in order to avoid mistreating patients and help improve their outcome and quality of life. However, prospective studies need to be conducted in order to assess treatment modalities in patients with acute stroke and a newly-diagnosed primary brain tumor.

\section{Additional Information}

\section{Disclosures}

Human subjects: Consent was obtained by all participants in this study. Conflicts of interest: In compliance with the ICMJE uniform disclosure form, all authors declare the following: Payment/services info: All authors have declared that no financial support was received from any organization for the submitted work. Financial relationships: All authors have declared that they have no financial relationships at present or within the previous three years with any organizations that might have an interest in the submitted work. Other relationships: All authors have declared that there are no other relationships or activities that could appear to have influenced the submitted work.

\section{References}

1. Fouladi M, Langston J, Mulhern R, et al.: Silent lacunar lesions detected by magnetic resonance imaging of children with brain tumors: a late sequela of therapy. J Clin Oncol. 2000, 18:824-831. 10.1200/JCO.2000.18.4.824

2. Obeid M, Ulane C, Rosenfeld S: Pearls \& Oy-sters: large vessel ischemic stroke secondary to glioblastoma multiforme. Neurology. 2010, 74:50-51. 10.1212/wnl.0b013e3181d7d66a

3. Pina S, Carneiro Â, Rodrigues T, Samões R, Taipa R, Melo-Pires M, Pereira C: Acute ischemic stroke 
secondary to glioblastoma: a case report. Neuroradiol J. 2014, 27:85-90. 10.15274/nrj-2014-10009

4. Rojas-Marcos I, Martin-Duverneuil N, Laigle-Donadey F, Tailibert S, Delattre JY: Ischemic stroke in patients with glioblastoma multiforme. J Neurol. 2005, 252:488-489. 10.1007/s00415-005-0665-7

5. Farkas A, Schlakman B, Khan M, Joyner D: Glioblastoma presenting with acute middle cerebral artery territory infarct. J Stroke Cerebrovasc Dis. 2018, 27:113-114. 10.1016/j.jstrokecerebrovasdis.2018.01.019

6. Lasocki A, Gaillard F: Ischaemic stroke in the setting of glioblastoma: a case series and review of the literature. Neuroradiol J. 2016, 29:155-159. 10.1177\%2F1971400916639603

7. Amelot A, Baronnet-Chauvet F, Fioretti E, Mathon B, Cornu P, Nouet A, Chauvet D: Glioblastoma complicated by fatal malignant acute ischemic stroke: MRI finding to assist in tricky surgical decision. Neuroradiol J. 2015, 28:483-487. 10.1177/1971400915598073

8. Kamiya-Matsuoka C, Cachia D, Yust-Katz S, Rodriguez YA, Garciarena P, Rodarte EM, Tremont-Lukats IW: Ischemic stroke in patients with gliomas at The University of Texas-M.D. Anderson Cancer Center . J Neurooncol. 2015, 125:143-148. 10.1007/s11060-015-1880-4

9. Chen H, Cebula H, Schott R, Dietemann JL, Froelich S: Glioblastoma multiforme presenting with ischemic stroke: case report and review of the literature. J Neuroradiol. 2011, 38:304-307. 10.1016/j.neurad.2011.01.008

10. Fraum TJ, Kreisl TN, Sul J, Fine HA, Iwamoto FM: Ischemic stroke and intracranial hemorrhage in glioma patients on antiangiogenic therapy. J Neurooncol. 2011, 105:281-289. 10.1007\%2Fs11060-011-0579-4

11. Kreisl TN, Toothaker T, Karimi S, DeAngelis LM: Ischemic stroke in patients with primary brain tumors . Neurology. 2008, 70:2314-2320. 10.1212/01.wnl.0000314648.82924.6f

12. Dobkin BH: Stroke associated with glioblastoma. Bull Clin Neurosci. 1985, 50:111-118.

13. Zuchner S, Kawohl W, Sellhaus B, Mull M, Mayfrank L, Kosinski CM: A case of gliosarcoma appearing as ischaemic stroke. J Neurol Neurosurg Psychiatry. 2003, 74:364-366. 10.1136/jnnp.74.3.364

14. Aoki N, Sakai T, Oikawa A, Takizawa T, Koike M: Dissection of the middle cerebral artery caused by invasion of malignant glioma presenting as acute onset of hemiplegia. Acta Neurochr. 1999, 141:1005-1008. 10.1007/s007010050408

15. Colin C, Voutsinos-Porche B, Nanni I, et al.: High expression of cathepsin B and plasminogen activator inhibitor type-1 are strong predictors of survival in glioblastomas. Acta Neuropathol. 2009, 118:745-754. 10.1007/s00401-009-0592-2

16. Etgen T, Steinich I, Gsottschneider L: Thrombolysis for ischemic stroke in patients with brain tumors . J Stroke Cerebrovasc Dis. 2014, 23:361-366. 10.1016/j.jstrokecerebrovasdis.2013.05.004 